\title{
PEMBANGUNAN SISTEM DESAIN BATIK PARANG DENGAN KURVA BEZIER
}

\section{Design System for Batik Parang Using Bezier Curve}

\author{
Widi Hapsari dan Nugroho Agus Haryono \\ Program Studi Informatika, Fakultas Teknologi Informasi Universitas Kristen Duta Wacana \\ Jl. Wahidin No. 5 - 25 Yogyakarta 55224
}

Korenspondesi Penulis
Email : widi@staff.ukdw.ac.id
Naskah Masuk : 07 Januari 2020

Revisi : 04 April 2020

Disetujui : 20 Mei 2020

Kata kunci: desain batik, batik parang, sistem desain

Keywords: batik design, batik parang, design system

\begin{abstract}
ABSTRAK
Batik Parang merupakan salah satu keanekaragaman motif batik yang memiliki pola hias bergaris miring dan berjajar. Parang termasuk jenis motif batik geometris yang dibentuk dari 2 unsur yaitu parang dan mlinjon. Kemiringan pada Parang membentuk pola dengan sudut 45 derajat. Saat ini dibutuhkan waktu yang lama untuk menyalin gambar desain (ngeblat) dan menduplikasi motif secara manual. Perekayasaan ini bertujuan membentuk sistem desain batik parang secara interaktif dengan memanfaatkan ornamen motif yang disimpan dalam database. Gen parang dan mlinjon yang tersimpan dihasilkan dari pola yang dibentuk menggunakan kurva Bezier. Pembentukan variasi kurva Bezier diperoleh dari penempatan sejumlah titik-titik kontrol. Penyimpanan setiap gen parang dan mlinjon berupa titik-titik kontrol dari kurva. Aplikasi ini mengambil gen motif dari database yang kemudian disusun secara bervariatif dengan mengatur arah kemiringan dan jarak motif yang berjajar. Hasil yang diperoleh adalah bermacam-macam motif Parang berdasarkan ornamen hasil pembentukan kurva Bezier. Desain yang diperoleh dari rekayasa ini sudah dibuat mirip dengan pustaka motif batik yang ada.
\end{abstract}

\section{ABSTRACT}

Parang Batik is one of batik motifs that has slanting parallel rows. Parang is a type of geometric batik. Parang consist of two elemen, parang and mlinjon. The slope of Parang forms angle pattern 45 degree.It takes a long time to copy the design (ngeblat) and duplicate the motif manually. This research aim to produces an Parang batik design system using ornamental motifs stored in a database. Parang and Mlinjon motif are composed of patterns by Bezier curves. The curve is formed based on the control points given. The various of these points position will obtain various curves. System can get motif from database then arrange them by adjusting the direction of the slope and the distance of the lined motif. The results obtained are various Parang motifs based on the ornaments resulting from the Bezier curve.The design obtained similar to existing parang batik motif libraries. 
IKh Dinamika Kerajinan dan Batik: Majalah Ilmiah. Vol. 37 No. 2, Desember 2020, hal. 127 - 144

\section{PENDAHULUAN}

Batik tradisional merupakan identitas tekstil/kain lokal yang kuat dengan berbagai corak daerah yang merefleksikan pentingnya hirarki dalam masyarakat Jawa. Batik tradisional juga memiliki peran dalam pesan kehidupan dalam tradisi jawa seperti kelahiran, pernikahan, dan kematian dengan ciri khas simbol dan pola motif khusus (Eskak \& Salma, 2018). Pada masa lampau, batik Yogyakarta hanya dipakai oleh lapisan masyarakat sebagai identitas untuk strata sosial tertentu. Saat ini setiap orang dapat mengenakan busana batik tanpa mempedulikan strata sosial yang melekat pada individu (Supriono, 2016) . Dalam perkembangannya batik masa kini tidak hanya berupa kain sandang yang bermotif indah tetapi juga kain untuk berbagai keperluan interior (Sartika, Eskak, \& Sunarya, 2017). Batik menjadi ekspresi kebudayaan masyarakat yang tidak hanya bersifat bendawi saja tetapi lebih kepada pengertian makna, nilai dan simbolnya. Pola parang dan lereng adalah pola batik geometris dengan kemiringan $45^{\circ}$. Perbedaan prinsip pola parang dan lereng adalah pada ragam hias penyusunnya, untuk pola parang selalu mengandung ragam hias mlinjon, sedangkan untuk pola lereng tidak ada ragam hias mlinjon (Badan Penelitian dan Pengembangan Industri Balai Besar Kerajinan \& Batik, 2009).

Motif hias dalam batik adalah unsurunsur atau elemen rupa yang tersusun membentuk gambar datar atau dua dimensi dalam lembaran kain. Unsur-unsur rupa utamanya adalah garis-garis yang nampak membentuk suatu komposisi karya desain motif (Salma, Eskak, \& Wibowo, 2016). Motif batik berdasarkan proses penciptaannya ada ada tiga yaitu motif klasik, motif pengembangan, dan motif modern (Salma,2019). Motif batik memiliki tiga unsur yaitu: ornamen utama, ragam hias pengisi, dan isen motif batik. Untuk memperoleh motif utama dapat dilakukan secara visual maupun menggunakan teknologi digital (Hapsari \& Haryono, 2016). Pengamatan terhadap unsur-unsur penyusun batik memberikan gagasan untuk mengembangkan sistem pembuatan desain batik secara digital dengan menggunakan bantuan teknologi informasi. Li dkk membuat inovasi desain batik secara interaktif dengan model evolusioner ( $\mathrm{Li}, \mathrm{Hu}$, \& Yao, 2009), Perpaduan seni dan sains melalui pembuatan desain batik Fraktal (Hariadi, Lukman, \& Destiarmand, 2013) , (Margried, 2015) , Pengembangan model desain motif batik tulis berbasis kurva Bezier (Arsiwi \& Wibisono, 2016), Yuan menyusun pola batik butterfly menggunakan geometri fractal. (Yuan, Lv, \& Huang, 2016) , Pengembangan inovasi untuk pola geometri (Sukamto \& Setiawan, 2017) , Pembuatan sistem desain batik truntum (Hapsari \& Haryono, 2018), Pembuatan sistem desain batik dengan komputasi matematis (Hapsari \& Haryono, 2018). Pembuatan desain parang secara manual membutuhkan waktu yang relatif lama dalam mengeblat/menyalin gambar, dan dalam menduplikasi motif. Pemanfaatan teknologi informasi untuk membangun desain suatu motif batik akan membantu para desainer mengembangkan kreativitas dan menghemat waktu desain. Teknologi komputer dapat membantu desainer batik untuk mensimulasikan hasil desainnya di layar komputer (Wibisono \& Toha, 2001). 
IKh Dinamika Kerajinan dan Batik: Majalah Ilmiah. Vol. 37 No.2, Desember 2020, hal. 127 - 134

Terdorong dengan gagasan pengembangan sistem desain batik secara digital, maka perlu dilakukan perancangan sistem yang bertujuan untuk mengembangkan sistem desain batik Parang dengan bantuan komputer. Parang menjadi pilihan motif karena cara mendesain parang yang sudah sistematis, yaitu penentuan parang dan penentuan mlinjon dengan pola geometris yang khas. Pendekatan perekayasaan dilakukan dengan menggunakan fungsi matematis kurva Bezier. Dengan menggunakan kurva Bezier dapat dibentuk berbagai macam kurva sesuai dengan titik-titik kontrolnya seperti dalam Gambar 1 (Sederberg, 2012).

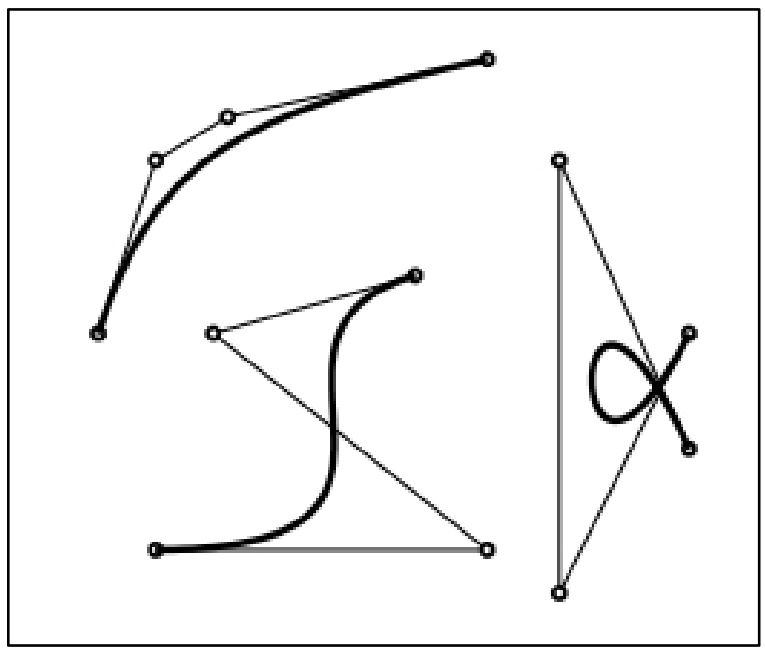

Gambar 1. Contoh kurva Bezier

Hasil perekayasaan berupa sistem komputer desain batik parang dengan beberapa pilihan model parang, model mlinjon, model arah kemiringan, dan model single-double, disertai dengan fitur pengaturan jarak motif dan skala parang.

\section{METODOLOGI PEREKAYASAAN}

Langkah awal perekayasaan dilakukan dengan mempelajari proses dalam mendesain batik Parang melalui studi pustaka. Perekayasaan dilanjutkan dengan membuat komponen-komponen yang dibutuhkan dalam membuat suatu motif parang. Sistem dibuat dengan menggunakan software Matlab R2017b. Pembuatan motif parang dan mlinjon dilakukan dengan menggunakan fungsi Bezier. Pengujian keberhasilan sistem dilihat secara manual dengan cara membandingkan gambar hasil sistem dengan batik parang yang ada dalam pustaka.

\section{Bahan dan Alat}

Sistem desain dibangun dalam model GUI dengan menggunakan software Matlab $R 2017 b$. File data yang digunakan ada dua buah. File pertama adalah "dataParang.mat" yang berisi kumpulan titik-titik penyusun kurva bezier pembentuk suatu motif parang. File data yang kedua adalah "dataMlinjon.mat" yang berisi kumpulan titik-titik penyusun kurva bezier pembentuk mlinjon. Bentuk-bentuk parang yang dibuat diambil dari pustaka batik yang dikeluarkan oleh Balai Besar Kerajinan \& Batik Yogyakarta (Badan Penelitian dan Pengembangan Industri Balai Besar Kerajinan \& Batik, 2009).

\section{Perancangan Sistem}

Sistem dirancang dalam model interaktif dengan pengguna untuk memilih parang dari data parang dan memilih mlinjon dari data mlinjon. Pengguna juga diminta untuk interaksi dalam mengatur jarak dan memilih model layout arah maupun jenis single atau double. Arsitektur sistem diberikan dalam Gambar 2. 
clKh Dinamika Kerajinan dan Batik: Majalah Ilmiah. Vol. 37 No. 2, Desember 2020, hal. 137 - 134

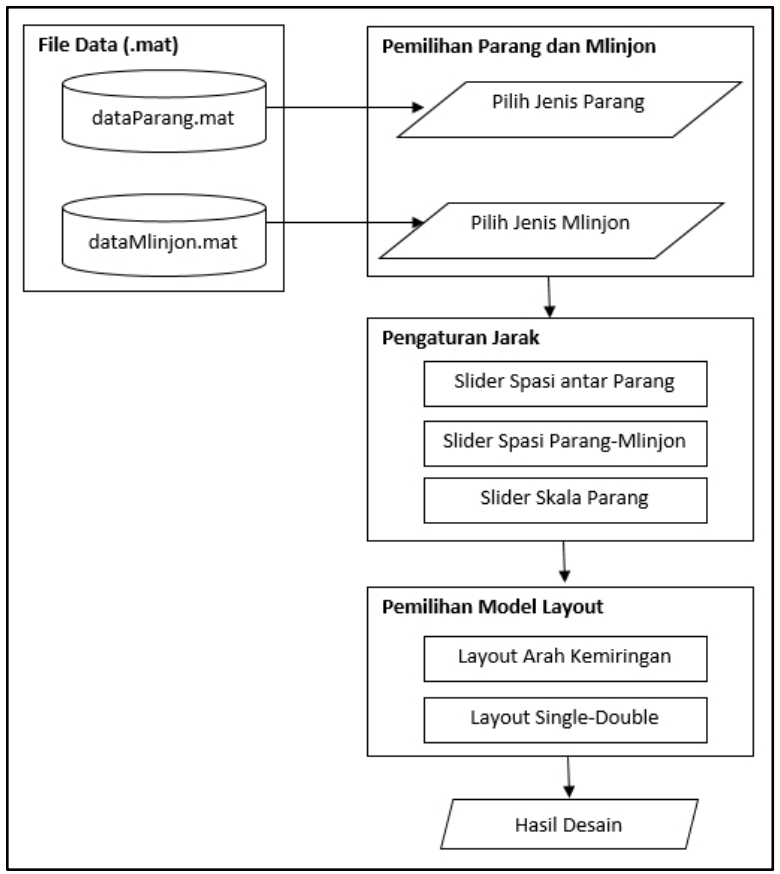

Gambar 2. Arsitektur Sistem Desain Batik Parang

\section{Pembuatan Parang dan Mlinjon dalam format .mat}

File dataParang.mat dan file dataMlinjon berisi empat field, berturutturut berisi: kumpulan titik-titik kontrol bezier, nama Parang/Mlinjon, Tinggi Parang, dan Lebar Parang. Tinggi dan lebar parang ikut disimpan dalam file untuk menyeragamkan ukuran standar parang/mlinjon satu dengan yang lainnya. Ukuran ini dapat diubah secara interaktif menggunakan slider skala Parang. Pembuatan jenis parang/mlinjon dilakukan dengan memanfaatkan fungsi Bezier. Langkah pembuatannya dilakukan dengan cara mengambil titik-titik penting yang ada dalam model parang. Titik-titik yang diambil berupa titik ujung dari kurva-kurva pembentuk motif parang. Titik-titik tersebut ditambah dengan beberapa titik kontrol untuk membentuk beberapa kurva Bezier penyusun parang/mlinjon. Tabel 1 . Menunjukkan contoh kumpulan titik-titik bezier untuk menghasilkan model Parang Tuding.

Tabel 1. Titik Bezier dan Parang Tuding

\begin{tabular}{cll}
\hline $\begin{array}{c}\text { Titik-titik } \\
\text { bezier }\end{array}$ & Keterangan & $\begin{array}{c}\text { Hasil Parang } \\
\text { Tuding }\end{array}$ \\
\hline $279,249,228$ & Setiap kurva & \multicolumn{2}{c}{ Parang Tuding } \\
$268,277,307$, & bezier & \\
$281,249+28$ & disusun oleh & 200 \\
$2,244,213,26$ & empat titik. & 100 \\
$4,288,324,28$ & Kurva bezier & 260280300 \\
$2,244+251,1$ & yang satu & \\
$10,280,57,23$ & dengan yang & \\
$7,232,284,24$ & lain & \\
$1+251,271,2$ & dipisahkan & \\
$60,140,265,8$ & dengan tanda & \\
$6,252,111 '$ & ' $+'$ \\
\hline
\end{tabular}

Persamaan parameter Bezier yang digunakan dalam perekayasaan ini adalah Bezier derajat tiga yang diberikan pada persamaan [1] (Sederberg, 2012)

$$
P(t)=m_{0}(t) P_{0}+m_{1}(t) P_{1}+m_{2}(t) P_{2}+m_{3}(t) P_{3}
$$

Dengan

$m_{0}(t)=(1-t)^{3}, m_{1}(t)=3 t(1-t)^{2}, m_{2}(t)=3 t^{2}(1-$

$t), m_{3}(t)=t^{3}$

dengan tnilai parameter antara 0 sampai dengan 1.

Kurva tersebut dikembangkan dari kurva Bezier derajat $n$ yang memiliki titik kontrol sebanyak $n+1$ dengan fungsi blending dinotasikan oleh $\mathrm{B}_{\mathrm{i}}^{\mathrm{n}}(\mathrm{t})$ pada persamaan [2].

$$
B_{i}^{n}(t)=\left(\begin{array}{l}
n \\
i
\end{array}\right)(1-t)^{n-i} t^{i}, i=0,1,2, \ldots \ldots, n
$$

\section{Membangun pembatas antara parang} dan mlinjon

Pembuatan pembatas antara parang dan mlinjon dilakukan dengan membangun kurva bezier derajat tiga. Titik pertama adalah titik ujung koordinat Parang ke-k, 
titik keempat adalah titik ujung koordinat Parang berikutnya. Titik kedua dan titik ketiga diletakkan pada sepertiga bagian dan dua pertiga bagian dari antara kedua parang dengan sedikit pergeseran arah sumbu-Y untuk mendapatkan kelengkungan sesuai dengan pustaka.

\section{Membangun layout model motif Parang}

Pembuatan model layout parang disusun dalam tiga bagian, yaitu bagian Parang, bagian mlinjon dan bagian pembatas. Layout kemiringan $45^{\circ}$ diberi dua pilihan, yaitu ke kanan atas dan ke kanan bawah. Model Parang diberi dua pilihan, yaitu: single dan double (bolak-balik).

\section{HASIL DAN PEMBAHASAN}

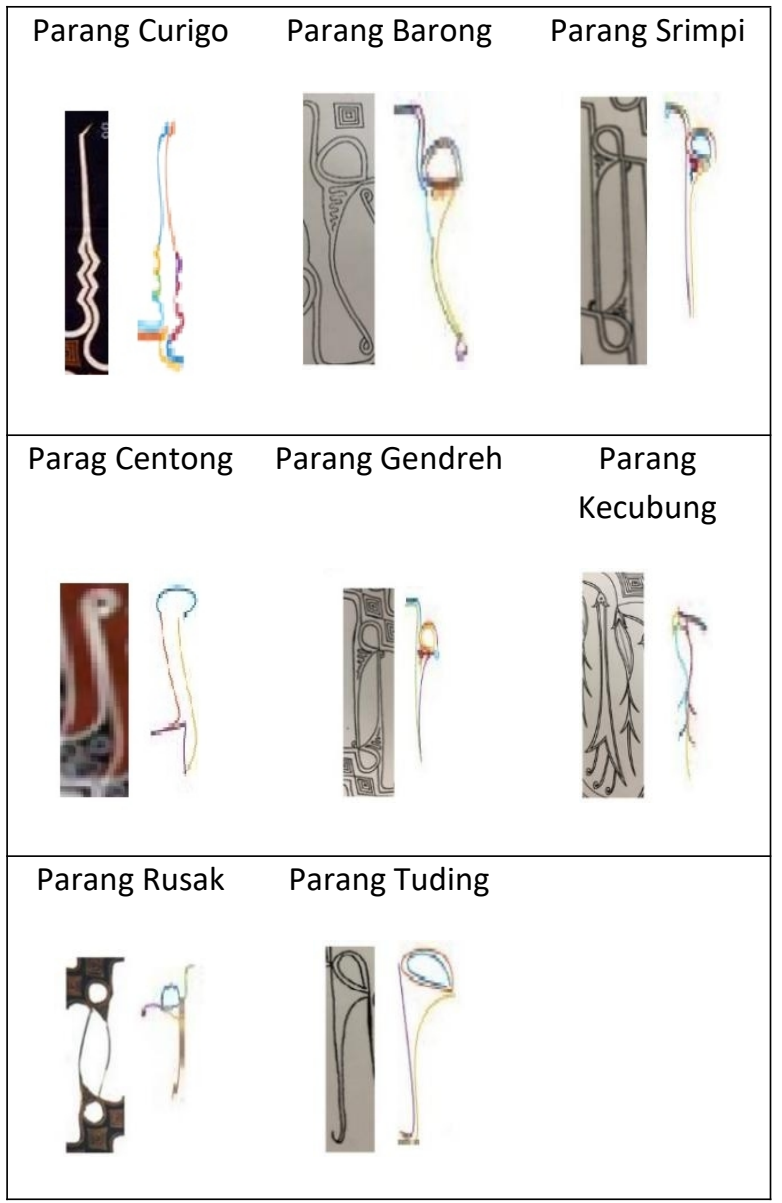

Gambar 3. Contoh Pilihan Parang

Sistem Desain Batik Parang yang dibuat menyediakan file dataParang.mat yang berisi data parang. Contoh hasil keluaran data parang yang bisa dipilih pengguna diberikan dalam Gambar 3.

Data gambar mlinjon dipilih oleh pengguna dari file dataMlinjon.mat. Contoh gambar mlinjon yang diambil dari motif parang rusak, parang kembang kecubung, parang centong dan parang tuding diberikan dalam Gambar 4.

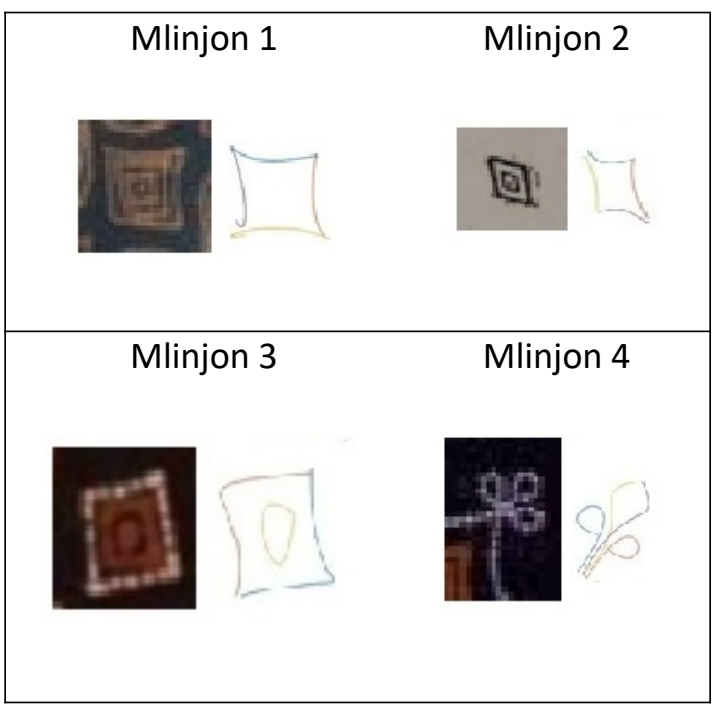

Gambar 4.Contoh Pilihan Mlinjon

Tampilan sistem dapat dilihat pada Gambar 5. Dalam sistem diberikan fasilitas menu berupa Pemilihan Gambar Parang, Pemilihan Gambar Mlinjon, Pengaturan Jarak dan Model Layout. Menu Pemilihan Gambar untuk parang dan mlinjon dilakukan dengan mengambil data yang disimpan dalam file .mat. Menu Pengaturan Jarak berisi 3 komponen pengatur yaitu Spasi Ke Kanan, Spasi Parang Mlinjon dan Skala Parang. Komponen Spasi Ke Kanan dipakai untuk mengatur jarak antar parang sehingga diperoleh desain dengan jarak antar parang yang sesuai. Menu Spasi Parang Mlinjon dipakai untuk mengatur 
jarak antara parang dengan mlinjon. Menu Skala Parang disediakan agar pengguna mendapatkan desain yang bervariasi pada ukuran parang. Menu terakhir pada sistem adalah Model Layout, yang berisi pilihan Layout Arah dan Layout Model. Pilihan Layout arah adalah arah ke kanan atas dan arah ke kanan bawah. Sedangkan pilihan Layout Model adalah single dan double (bolak balik).

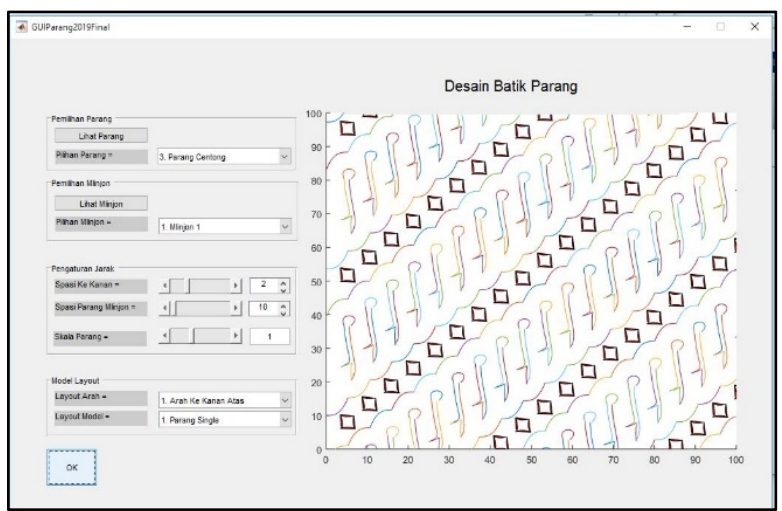

Gambar 5. Tampilan Sistem Parang Centong Arah Kanan Atas

\section{Pengujian Hasil Sistem}

Dalam perekayasaan ini hasil desain keluaran sistem dibandingan dengan gambar-gambar yang ada dalam pustaka. Tabel 2 memberikan contoh hasil perbandingan desain hasil sistem yang dibuat dan gambar parang dari pustaka, berupa Parang Centong, Parang Gendreh, dan Parang Curigo.

Dari gambar pustaka yang diacu, sistem sudah mampu mengambil sebagian besar ornamen dari motif tersebut, terutama bagian parang dan mlinjon, dan sudah berhasil menduplikasi ornamen dalam model layout tertentu.Sistem masih memiliki kekurangan dalam menghasilkan bentuk-bentuk ragam hias yang sama persis dengan pakem. Hal ini bisa menjadi masukan bagi para peneliti untuk mengembangkan sistem lebih lanjut. Proses uji pendapat dengan ahli batik mengenai hasil desain oleh sistem belum dilakukan. Sistem bisa menghasilkan hasil desain yang lebih cepat dibandingkan secara manual yang bisa menjadi salah satu solusi dalam mempercepat waktu proses desain.

Tabel 2.Perbandingan Sistem dan Pustaka
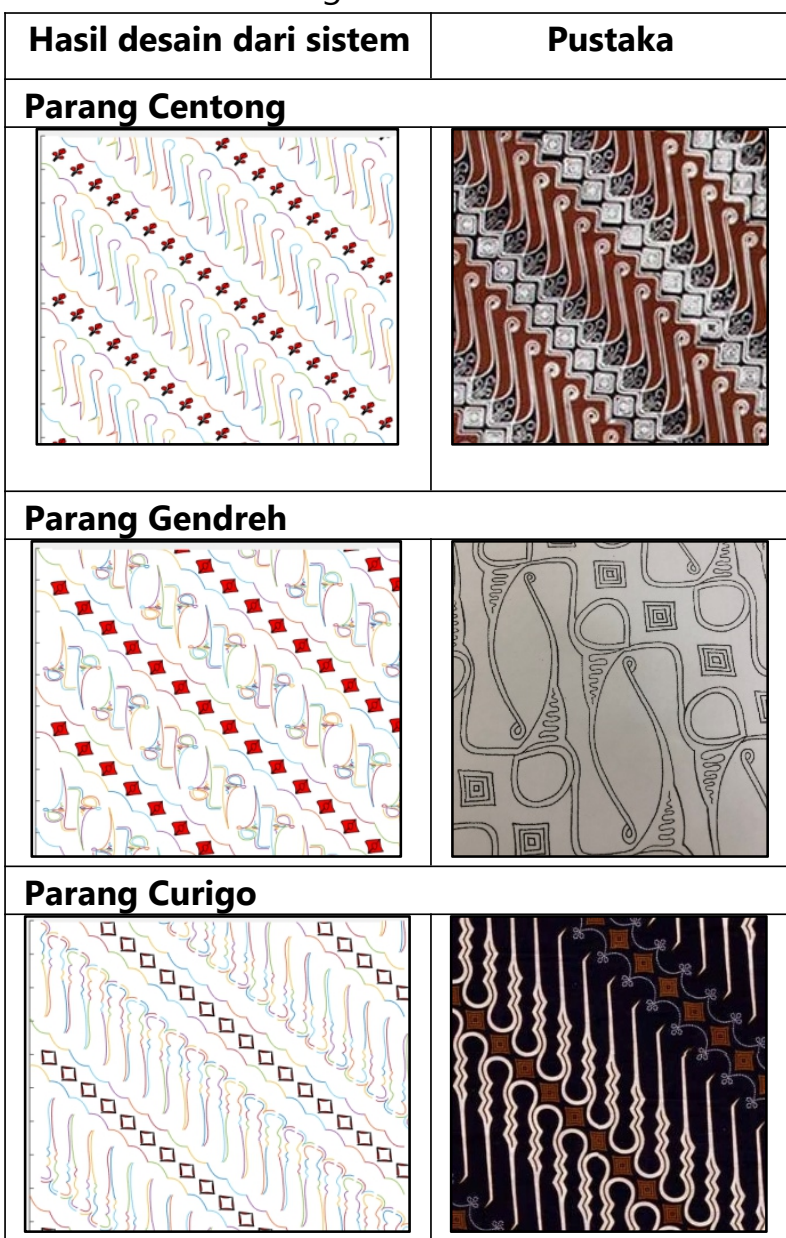

\section{KESIMPULAN DAN SARAN}

\section{Kesimpulan}

Sistem telah berhasil dibuat dengan menggunakan dua buah file format .mat untuk menyimpan data parang dan data mlinjon. Fitur interaksi dengan pengguna meliputi pemilihan parang/mlinjon, pengaturan jarak, pengaturan skala, dan pemilihan model layout. Hasil perbandingan desain keluaran sistem sudah mirip dengan 
clKh Dinamika Kerajinan dan Batik: Majalah Ilmiah. Vol. 37 No.2, Desember 2020, hal. 127 - 134

gambar pustaka. Kurva Bezier dapat dimanfaatkan untuk membangun kelengkungan bagian-bagian parang, mlinjon, dan pembatas antara mlinjon dan parang.

\section{Saran}

Untuk perekayasaan ke depannya, sistem dapat dikembangkan lebih lanjut untuk desain batik parang untuk mengakomodasi model-model layout yang lainnya, seperti bolak-balik sumbu-x menggunakan rotasi 90 derajat. Sistem dapat juga dilengkapi dengan penambahan fitur pewarnaan dan jenis/style garis kurva. Kurva Bezier yang digunakan bisa dipilih dalam derajat tertentu untuk semakin menyerupai pustaka yang ada.

\section{KONTRIBUSI PENULIS}

Penulis pertama dan penulis kedua merupakan peneliti utama pada penelitian ini.

\section{UCAPAN TERIMA KASIH}

Penulis mengucapkan terima kasih kepada Fakultas Teknologi Informasi UKDW yang telah memberikan fasilitas penelitian dan kesempatan bagi penulis melakukan penelitian, dan kepada Lembaga Penelitian dan Pengabdian Masyarakat LPPM UKDW yang telah memberikan dana penelitian. Kiranya Tuhan Yang Maha Esa memberkati kita dalam mengembangkan pengetahuan yang bermanfaat bagi masyarakat.

\section{DAFTAR PUSTAKA}

Arsiwi, P., \& Wibisono, M. (2016). Pengembangan Model Desain Motif Batik Tulis Hand-Drawn Berbasis Bezier Curve. Seminar Nasional Teknik Industri
Universitas Gadjah Mada (pp. TP-2 TP-9). Yogyakarta: Teknik Mesin dan Teknik Industri UGM.

Badan Penelitian dan Pengembangan Industri Balai Besar Kerajinan \& Batik. (2009). Batik, Citra Tradisi Indonesia: Kumpulan Motif Batik Tradisional Yogya dan Solo. Yogyakarta: Balai Besar Kerajinan \& Batik.

Eskak, E., \& Salma, I. R. (2018). Menggali Nilainilai Solidaritas Dalam Motif Batik Indonesia. Jantra, 13(2), 107-124.

Hapsari, W., \& Haryono, N. A. (2016). Segmentasi Warna Pada Batik Menggunakan Pendekatan HSV Dengan Teknik Linkage. Konferensi Nasional Teknologi Informasi dan Komunikasi (KNASTIK) (pp. 268-274). Yogykarta: Fakultas Teknologi Informasi UKDW.

Hapsari, W., \& Haryono, N. A. (2018). Pembuatan Sistem Desain Batik dengan Komputasi Matematis. Prosiding Semnastik (pp. 449-457). Palembang: PPP-Universitas Bina Darma Press, UBD, Palembang, Indonesia.

Hapsari, W., \& Haryono, N. A. (2018). Sistem Interaktif Desain Batik Truntum. Research Fair UNISRI (pp. 106-111). Surakarta: Slamet Riyadi University, Surakarta, Indonesia.

Hariadi, Y., Lukman, M., \& Destiarmand, A. H. (2013). Batik Fractal: Marriage of Art and Science. ITB J. Vis. Art \& Des., 84-93.

Li, Y., Hu, C.-J., \& Yao, X. (2009, November). Innovative Batik Design with an Interactive Evolutionary Art System. Journal of Computer Science and Technology, 1035-1047.

Margried, N. (2015). Batik Fractal Community: Creative Engagement through Technology. Procedia - Social and Behavioral Sciences, 214-222.

Salma, I. R. (2019). REVIEW: PENGEMBANGAN BATIK MOTIF KHAS DAERAH DI BALAI BESAR KERAJINAN DAN BATIK. Dinamika Kerajinan Dan Batik, 36(2), 149-162.

Salma, I. R., Eskak, E., \& Wibowo, A. A. (2016). Kreasi Batik Kupang. Dinamika Kerajinan Dan Batik, 33(1), 45-54. 
clKh Dinamika Kerajinan dan Batik: Majalah Ilmiah. Vol. 37 No. 2, Desember 2020, hal. 137 - 134

Sartika, D., Eskak, E., \& Sunarya, I. K. (2017). Uma Lengge Dalam Kreasi Batik Bima. Dinamika Kerajinan Dan Batik, 34(2), 7382.

Sederberg, T. W. (2012). Computer Aided Geometric Design. Utah: Brigham Young University, https://scholarsarchive.byu.edu/facpub/1.

Sukamto, A., \& Setiawan, A. (2017). Development Geometric Pattern Of Paradila Weaving Need Design Innovation. International Conference of Arts Language And Culter, (pp. 390-396). Surakarta.

Supriono, P. (2016). Ensiklopedia The Heritage of Batik : Identitas Pemersatu Kebanggan Bangsa. Yogyakarta: Andi Offset.

The Ministry of Culture and Tourism of The Republic of Indonesia. (2008). Indonesian Batik Transforming Tradition Into $A$ Modern Trend. Jakarta: PT. Adem Sari Tirta Buana.

Wibisono, A., \& Toha, I. S. (2001). Desain Batik Canting CAP Berbantuan Komputer. Jurnal Teknologi Industri, 1-12.

Yuan, Q., Lv, J., \& Huang, H. (2016). AutoGeneration Method of Butterfly Pattern of Batik Based on Fractal Geometry. International Journal of Signal Processing, Image Processing and Pattern Recognition, 9, 369-392. 